\title{
NEW FILLER FOR ELECTROCONTACT WELDING
}

Key words: electrocontact welding; filler tape; perforation; plastic deformation; welding strength.

\section{Authors' personal details}

1. Rivaz Masyagutov, Assistant, Department of Metal Technology and Machine Repair, Federal State Budgetary Educational Institution of Higher Education «Bashkir State Agrarian University», 450001, Ufa, 50-letiya Oktyabrya str., 34, phone: +7 (347) 228-07-71, e-mail: rivazm@yandex.ru.

2. Marat Nafikov, Doctor of Technical Sciences, Professor, Department of Mechanics and Machine Design, Federal State Budgetary Educational Institution of Higher Education «Bashkir State Agrarian University», 450001, Ufa, 50-letiya Oktyabrya str., 34, phone: +7 (347) 228-07-71, e-mail: nafikovmz@rambler.ru.

3. Ilnur Zagirov, Candidate of Technical Sciences, Associate Professor of the Department of Mechanics and Machine Design, Federal State Budgetary Educational Institution of Higher Education «Bashkir State Agrarian University», 450001, Ufa, 50-letiya Oktyabrya str., 34, phone: +7 (347) 228-07-71, e-mail: zagirych 22@mail.ru.

Effective methods of restoring worn parts are based on the method of seam welding by electrical contact methods (ECM). The demand for such technologies is explained by their simplicity, high quality of restoration, minimal subsequent mechanical processing, and favorable working conditions for the operator-welder. The steel wires, woven nets, metal powders are used as filler materials for ECM, but the most convenient and widespread type of additive is steel flat tapes. A wider industrial application of the ECM for steel tapes is constrained by a significant disadvantage of filler - its rigidity. Due to insufficient plastic deformation, the filler metal is weakly welded to the part, the operational characteristics of the restored shafts are low. To eliminate this drawback, the Bashkir State Agrarian University has developed a new perforated additive based on steel tape. Such an additive is easily deposited by the force of the tool during the passage of a current pulse, three-dimensional plastic deformation occurs, providing the most durable welding of the coating. The physical mechanism of the formation of strong metal bonds between the filler metal and the base metal of the part is disclosed. The analytical studies of the plastic deformation of the filler metal were carried out, the results of which allow us to determine the rational geometric parameters of the new perforated additive, namely: the initial thickness of the tape, the radius and pitch of the holes, the perforation coefficient.

() Масягутов Р.Ф., Нафиков М.З., Загиров И.И.

УДК 62-799

DOI: $10.31563 / 1684-7628-2020-54-2-100-105$

Ш.Ф. Нигматуллин, М.М. Разяпов, С.С. Акимов, Р.Ф. Самиков

\section{РАЗРАБОТКА СТЕНДА ДЛЯ ИСПЫТАНИЯ ПРЕДПУСКОВЫХ ПОДОГРЕВАТЕЛЕЙ СИЛОВЫХ АГРЕГАТОВ СЕЛЬСКОХОЗЯЙСТВЕННОЙ И СТРОИТЕЛЬНОЙ ТЕХНИКИ}

\author{
Ключевые слова: предпусковой подогреватель; стенд; диагностирование; горелка; темпера- \\ тура; термопары; датчик.
}

Введение. При эксплуатации автотракторной техники в условиях минусовых температур всегда имеется риск трудного запуска двигателя и повышенного эксплуатационного износа узлов и агрегатов [1]. Для того чтобы минимизировать такие последствия, применяются различные устройства и агрегаты, которые облегчают запуск двигателя. Самыми распространёнными являются автономные предпусковые подогреватели двигателя [16].
При эксплуатации в период минусовых температур было выявлено, что 60 \% отказов предпусковых подогревателей связано с некачественны топливом, ненадлежащим состоянием электроник, износом резинотехнических изделий, а также выходом из строя составных частей горелки подогревателя [3-5].

Цель исследования: создание рабочей модели стенда и проверка его работоспособности на различных режимах работы предпусковых 
подогревателей для выявления неисправности узлов и агрегатов без разбора. Снятие характеристик работы исправного подогревателя для сравнения их значений с подогревателем, бывшим в употреблении.

Материалы и методы исследования. Подогреватель Терммикс 15д-24 широко применяется для предпускового подогрева различных узлов и агрегатов автотракторной техники в условиях отрицательных температур [9].

Основными неисправностями данного устройства являются закоксовывание горелки подогревателя, возникающее по причине некачественного топлива, засорения воздушного тракта [6]. Последующая эксплуатация подогревателя с неисправной горелкой может повлечь за собой образование трещины в ней, выход из строя свечи накаливания, датчика пламени и как следствие возникновение пожара [8].

По этой причине требуется своевременно проводить регламентные работы, очищать засорившуюся горелку подогревателя, при необходимости сильного износа заменять сетку испарителя [7]. После проведенных операций предпусковой подогреватель необходимо проверить на исправную работу. Работоспособность подогревателя на различных режимах можно проверить с помощью стенда [11].

На кафедре автомобилей и машинно-тракторных комплексов Башкирского ГАУ была разработана и собрана модель стенда для диагностирования предпускового подогревателя (рисунок 1) различных производителей.

Для выявления работоспособности стенда для диагностирования подогревателей экспериментальные исследования были проведены с использованием двух подогревателей марки Терм- микс 15д-24, один из которых новый, не был в эксплуатации, другой эксплуатировался несколько сезонов [5]. В качестве теплоносителя использовались антифриз и масло.

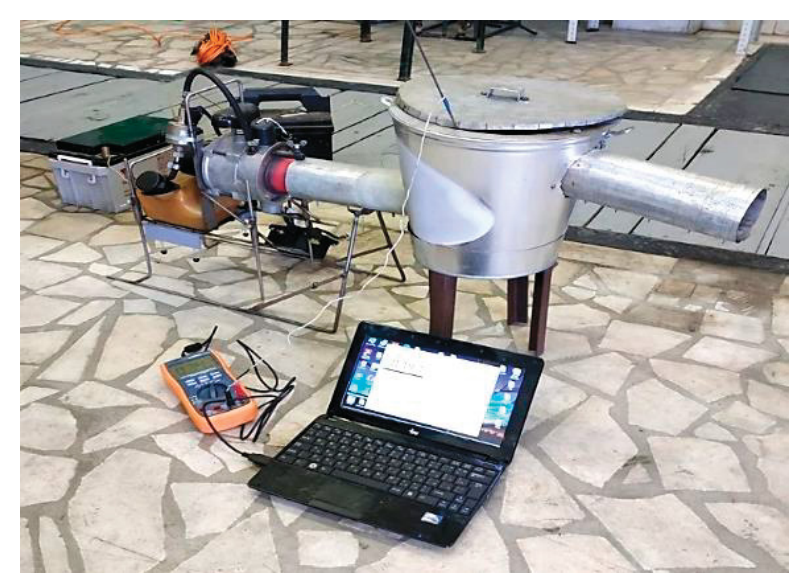

Рисунок 1

Экспериментальная модель стенда

для диагностирования предпускового подогревателя

Методика создания технологической карты заключается в том, что к стенду подключается новый предпусковой подогреватель Терммикс 15 д-24 (с техническими данными, представленными в таблице 1) и производится замер изменения температуры теплоносителей стенда в зависимости от времени работы подогревателя [15]. После измерения второго бывшего в употреблении подогревателя Терммикс 15д-24 полученные данные сравниваются. Проанализировав отклонения, делаем вывод о неисправностях предпускового подогревателя и возможных регламентных работах или заменах узлов и агрегатов в соответствии с руководством по эксплуатации данной модели [6].

Таблица 1 Технические характеристики предпускового подогревателя Терммикс 15д-24 [4]

\begin{tabular}{|l|c|}
\hline \multicolumn{1}{|c|}{ Характеристика } & Значение \\
\cline { 2 - 2 } & Терммикс 15д-24 \\
\hline Номинальное напряжение питания, В & 24 \\
\hline Температура горячих газов, ${ }^{\circ} \mathrm{C}$ & 700 \\
\hline Теплопроизводительность, кВТ & 15 \\
\hline Потребляемая мощность генератора, Вт & 70 \\
\hline Применяемое топливо & Дизельное топливо \\
\hline Расход топлива, л/час & 1,5 \\
\hline Режим запуска и остановки & Ручной \\
\hline Масса со всеми комплектующими, кг & 8 \\
\hline
\end{tabular}

На основе экспериментальных исследований данные были скорректированы и записаны в таблицу для последующего сравнения и выявления неисправности узлов и агрегатов предпускового подогревателя Терммикс 15д-24.

Измерения проводились при начальной температуре теплоносителя $+5{ }^{\circ} \mathrm{C}$ и до нагрева его до рабочей температуры в двигателе $+110{ }^{\circ} \mathrm{C}$. Объем резервуара рабочей жидкости теплооб- менника стенда составляет 5 литров. В качестве теплоносителя применялся антифриз.

В результате проведения исследований подогревателей Терммикс 15д-24 все полученные данные были обработаны и занесены в таблицу 2.

Из данных таблицы 2 видно, что новый подогреватель Терммикс 15д-24, имеющий теплопроизводительность 15 кВт, нагрел антифриз с +5 до $+110{ }^{\circ} \mathrm{C}$ за 9 мин 28 с. Бывший в исполь- 
зовании Терммикс 15 д- 24 нагрел с +5 до $+110{ }^{\circ} \mathrm{C}$ антифриз за 11 мин 15 с. По результатам серии экспериментов построен график (рисунок 2) зависимости времени нагрева рабочей жидкости до определенной температуры.

Из графика видно, что время нагрева антифриза бывшим в использовании подогревателем Терммикс 15д-24 больше, чем у нового подогревателя, отсюда делаем вывод, что подогреватель имеет неисправность и требует ремонта.

Диагностическими параметрами при проверке подогревателя являются $\Delta t$ и $\Delta T$. В ходе работы значения были скорректированы и со- ставлен тест-план проверки подогревателя Терммикс 15д-24.

После разбора было выявлено, что произошел прогар сетки подогревателя (рисунок 3), что препятствовало набору рабочей температуры на выходе пламени горелки.

После устранения неисправности произвели повторное тестирование бывшего в употреблении подогревателя Терммикс 15д-24. По полученным данным был построен график (рисунок 4) зависимости времени нагрева рабочей жидкости от температуры послеремонтного подогревателя Терммикс 15д-24.

Таблица 2 Данные экспериментальных исследований нового и бывшего в употреблении подогревателей Терммикс 15д-24

\begin{tabular}{|c|c|c|c|}
\hline \multirow{2}{*}{ Рабочая жидкость } & \multirow{2}{*}{ Период замера, сек } & \multicolumn{2}{|c|}{ Температура теплоносителя, ${ }^{\circ} \mathrm{C}$} \\
\cline { 2 - 4 } & & новый Терммикс 15д-24 & б/у Терммикс 15д-24 \\
\hline \multirow{5}{*}{ Антифриз } & 0 & 5 & 5 \\
\cline { 2 - 4 } & 60 & 21 & 21 \\
\cline { 2 - 4 } & 120 & 39 & 33 \\
\cline { 2 - 4 } & 180 & 55 & 45 \\
\cline { 2 - 4 } & 240 & 67 & 65 \\
\cline { 2 - 4 } & 300 & 78 & 87 \\
\cline { 2 - 4 } & 360 & 89 & 95 \\
\cline { 2 - 4 } & 420 & 96 & 102 \\
\cline { 2 - 4 } & 480 & 103 & 111 \\
\cline { 2 - 4 } & 540 & 110 & \\
\hline
\end{tabular}

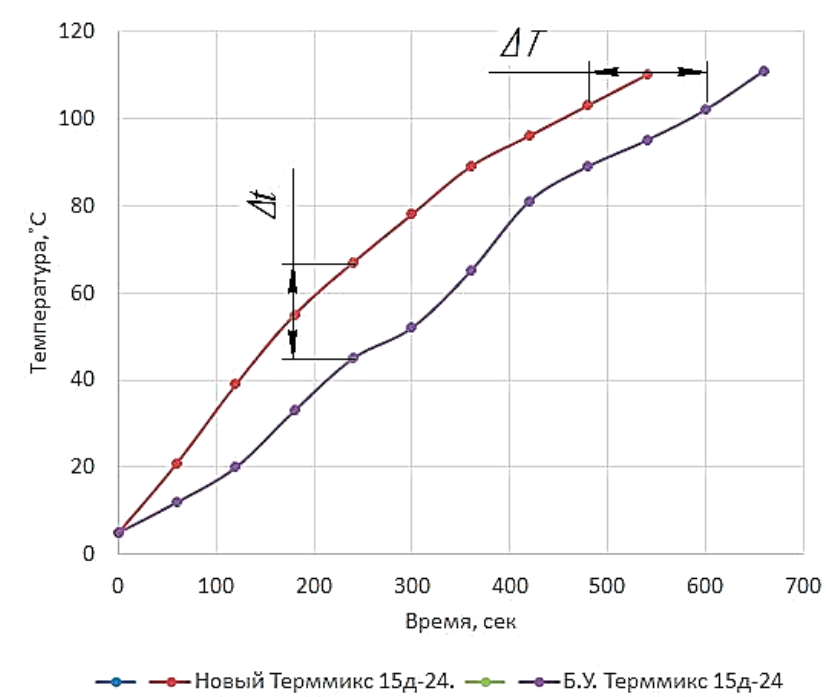

Рисунок 2

Зависимость времени нагрева рабочей жидкости от температуры Терммикс 15д-24

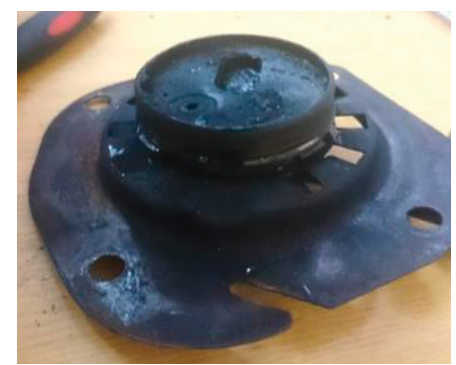

Рисунок 3

Прогар сетки подогревателя 


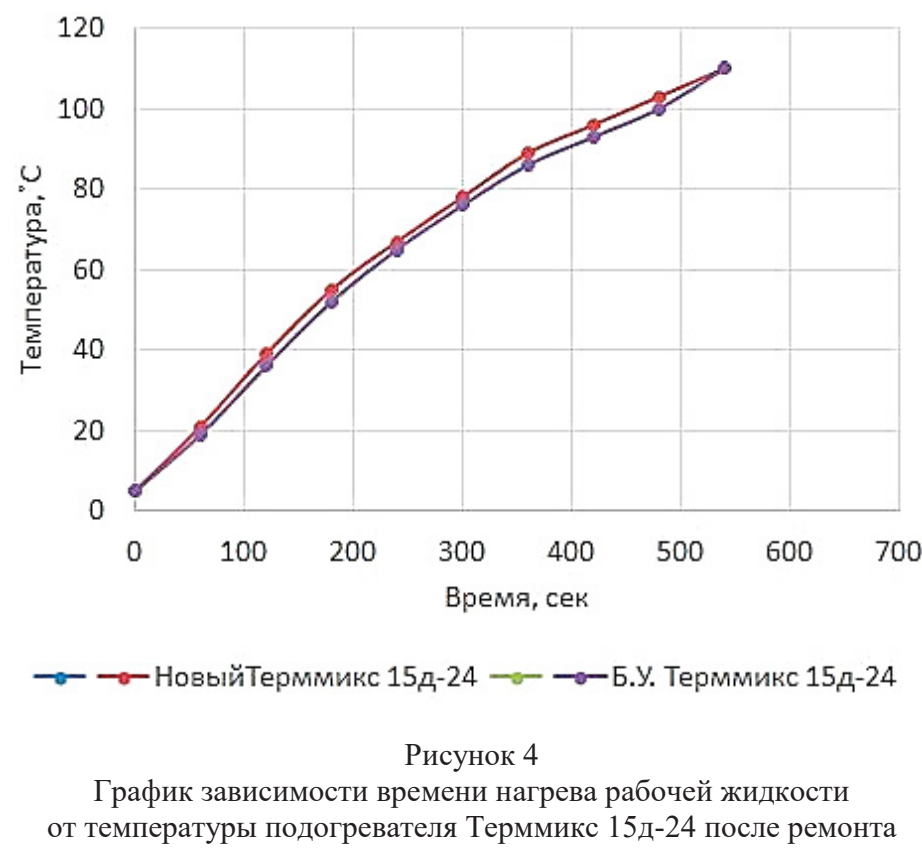

Из полученного графика видно, что после проведения ремонтных работ и последующего замера значения времени нагрева подогревателя идентичны значениям нового предпускового подогревателя Терммикс 15д-24.

Выводы. Разработан стенд для проверки подогревателей. Произведена серия опытов с использованием предпускового подогревателя
Терммикс 15д-24 с последующим ремонтом и повторной проверкой работоспособности узлов и агрегатов подогревателя. Полученные результаты свидетельствуют, что после проведения ремонтных работ и последующего замера значения времени нагрева подогревателя идентичны значениям нового предпускового подогревателя Терммикс 15д-24.

\section{Библиографический список}

1. Габитов, И.И. Интеллектуализация технического обслуживания и ремонта автотракторной и комбайновой техники [Текст] / И.И. Габитов // Вестник Башкирского государственного аграрного университета. 2018. № 3 (47). C. 13-17.

2. Габитов, И.И. Оптимизация процесса тепловой подготовки сельскохозяйственной техники в условиях низких температур [Текст]/ И.И. Габитов, А.В. Неговора, М.М. Рязапов, Д.А. Гусев // Технический сервис машин. 2019. № 1 (134). С. 122-130.

3. Инсафуддинов, С.3. Анализ способов удаленного непрерывного диагностирования технического состояния автотракторной и сельскохозяйственной техники [Текст] / С.3. Инсафуддинов, Т.Т. Фархутдинов, Ф.Г. Абдразаков // Современное состояние, традиции и инновационные технологии в развитии АПК: материалы международной научно-практической конференции в рамках XXIX международной специализированной выставки «Агрокомплекс2019» / Министерство сельского хозяйства Российской Федерации, Министерство сельского хозяйства Республики Башкортостан, ФГБОУ ВО «Башкирский государственный аграрный университет», ООО «Башкирская выставочная компания». Уфа, 2019. С. 92-97.

4. Неговора, А.В. Современная концепция тепловой подготовки автотракторной техники в условиях низких температур [Текст] / А.В. Неговора, М.М. Разяпов, С.3. Инсафуддинов // Вестник Башкирского государственного аграрного университета. 2018. № 4 (48). С. 135-141.

5. Неговора, А.В. Современные проблемы эксплуатации автомобилей в условиях низких температур независимо от климатической зоны [Текст] / А.В. Неговора, М.М. Разяпов, П.Г. Курдин, Ю.К. Филиппов, В.А. Токарев // Журнал автомобильных инженеров. 2017. № 4 (105). С. 3641.

6. Неговора, А.В. Исследование работоспособности системы смазки коробки передач $\mathrm{zf}$ 16s 1820 в условиях низких температур [Текст]/ А.В. Неговора, М.М. Разяпов // Фундаментальные основы научно-технической и технологической модернизации АПК (ФОНТиТМ-АПК-13): материалы Всероссийской научно-практической конференции. Уфа: Башкирский ГАУ, 2013. C. 241-246.

7. Неговора, А.В. Повышение эффективности работы жидкостного предпускового подо- 
гревателя [Текст] / А.В. Неговора, М.М. Разяпов, Н.А. Шерстнев // Технологии реновации машин и оборудования: материалы Всероссийской научно-практической конференции в рамках XI Промышленного салона и специализированных выставок «Промэкспо, станки и инструмент», «Сварка. Контроль. Диагностика». Уфа, 2016. C. $184-188$.

8. Самиков, Р.Ф. Повышение коэффициента полезного действия генераторов горячих газов [Текст] / Р.Ф. Самиков, М.М. Разяпов // Наука молодых - инновационному развитию АПК: материалы XI национальной научно-практической конференции молодых ученых. Уфа: Башкирский ГАУ, 2018. С. 263-267.

9. Разяпов, М.М. Повышение работоспособности агрегатов трансмиссии автотракторной техники в условиях низких температур [Текст]: дис. ... канд. техн. наук / М.М. Разяпов. Уфа: Башкирский ГАУ, 2013.

10. Разяпов, М.М. Снижение риска отказов мобильной сельскохозяйственной техники и транспортных средств в условиях низких температур [Текст] / М.М. Разяпов, Д.А. Гусев // Реновация машин и оборудования: материалы Всероссийской научно-практической конференции. Уфа, 2017. С. 160-166.

11. Самиков, Р.Ф. Совершенствование рабочего процесса генератора горячих газов терммикс-15д [Текст] / Р.Ф. Самиков // Проблемы технического сервиса в АПК: сборник научных трудов II студенческой всероссийской научнопрактической конференции. 2019. С. 84-90.

12. Черноиванов, В.И. Цифровые технологии и электронные средства в системе техниче- ского обслуживания и ремонта автотракторной и комбайновой техники [Текст] / В.И. Черноиванов, И.И. Габитов, А.В. Неговора // Труды ГОСНИТИ. 2018. Т. 130. С. 74-81.

13. Ildar I. Gabitov, Ildar D. Badretdinov, Salavat G. Mudarisov, Eduard R. Khasanov, Ramil L. Lukmanov, Ruslan R. Nasyrov, Marat F. Tuktarov, Dinar T. Atnagulov, Ildar A. Timeriashev and Viktor A. Pavlenko, 2018. Modeling the Process of Heap Separation in the Grain Harvester Cleaning System. Journal of Engineering and Applied Sciences, 13: 6517-6526. DOI: 10.3923/jeasci.2018. 6517.6526 .

14. Gabitov I.I., Negovora A.V., Khasanov E.R., Galiullin R.R., Farhshatov M.N., Khamaletdinov R.R., Martynov V.M., Gusev D., Yunusbaev N.M., Razyapov M.M. Risk reduction of thermal damages of units in machinery heat preparation for load acceptance. Journal of Engineering and Applied Sciences. 2019. T. 14. № 3. P. 709716.

15. Insafuddinov S.Z., Valiev A.R., Plotnikov D.O. Increase diesel engine performance by turning off cylinders. Journal of Advanced Research in Technical Science. 2019. № 16. P. 50-55.

16. Gabitov I.I., Insafuddinov S.Z., Kharisov D.D., Safin F.R., Negovora A.V., Yunusbaev N.M., Akhmetov A.F., Farhutdinov T., Sharafeev A. Diagnostics and regulation of fuel equipment of diesels on stands with injection to medium with counter-pressure. Journal of Engineering and Applied Sciences. 2018. T. 13. № S11. P. 87828788.

\section{Сведения об авторах}

1. Нигматуллин Шамиль Файзрахманович, кандидат технических наук, доцент кафедры автомобилей и машинно-тракторных комплексов, ФГБОУ ВО Башкирский ГАУ, 450001, г. Уфа, Ул. 50-летия Октября, 34, e-mail: shamil.bosch@mail.ru.

2. Разяпов Махмут Магдутович, кандидат технических наук, доцент кафедры автомобилей и машинно-тракторных комплексов, ФГБОУ ВО Башкирский ГАУ, 450001, г. Уфа, ул. 50-летия Октября, 34, e-mail: mahmut.87@mail.ru.

3. Акимов Сергей Сергеевич, магистр кафедры автомобилей и машинно-тракторных комплексов, ФГБОУ ВО Башкирский ГАУ, 450001, г. Уфа, ул. 50-летия Октября, 34, e-mail: hukum2@mail.ru.

4. Самиков Руслан Фанзилович, магистр кафедры автомобилей и машинно-тракторных комплексов, ФГБОУ ВО Башкирский ГАУ, 450001, г. Уфа, ул. 50-летия Октября, 34.

При эксплуатации автомобиля в условиях минусовых температур всегда имеется риск трудного запуска двигателя и повышенного эксплуатационного износа узлов и агрегатов автомобиля. Для снижения таких влияний применяются различные устройства и агрегаты, задача которых - облегчить запуск двигателя и минимизировать пусковые износы. Наиболее распро- странёнными среди них являются автономные предпусковые подогреватели двигателя. Опыт эксплуатации в зимний период показал, что $60 \%$ отказов предпусковых подогревателей связано с состоянием электроники, качеством топлива, износом резинотехнических изделий и выходом из строя составных частей горелки (закоксовывание, трещины, прогар). В условиях 
реальной эксплуатации данных устройств происходит износ составных частей узлов и агрегатов предпускового подогревателя. Для того чтобы провести диагностирование предпускового подогревателя, требуется стенд для проверки работоспособности на номинальном режиме работы. В данной статье предлагается разработка стенда для диагностирования предпускового подогревателя и производится измерение времени нагрева тестируемой жидкости до рабочей температуры. Для проведения измерений применяются два предпусковых подогревателя
Терммикс 15д-24, один новый, второй бывший в употреблении, для сравнения результатов между собой. В качестве рабочей жидкости в резервуаре теплообменника применяется антифриз. В результате проведения опытов и сравнения полученных значений времени нагрева тестируемой жидкости до определенной температуры было видно, что при помощи данного стенда возможно диагностировать и проверять работоспособность предпусковых подогревателей. Также был составлен тест-план проверки подогревателя Терммикс 15 д-24.

Sh. Nigmatullin, M. Razyapov, S. Akimov, R. Samikov

\title{
DEVELOPMENT OF A STAND FOR TESTING PRE-STARTING HEATERS OF POWER UNITS OF AUTOTRACTOR AND CONSTRUCTION EQUIPMENT
}

\author{
Key words: pre-heater; stand; diagnosis; burner; temperature; thermocouples; sensor.
}

\section{Authors' personal details}

1. Shamil Nigmatullin, Candidate of Technical Sciences, associate Professor of the Department of automobiles and machine-tractor complexes, Federal State Budgetary Educational Institution of Higher Education «Bashkir State Agrarian University», 450001, Ufa, 50-letiya Oktyabrya St., 34, e-mail: shamil.bosch@mail.ru.

2. Makhmut Razyapov, Candidate of Technical Sciences, associate Professor of the Department of automobiles and machine-tractor complexes, Federal State Budgetary Educational Institution of Higher Education «Bashkir State Agrarian University», 450001, Ufa, 50-letiya Oktyabrya St., 34, e-mail: mahmut.87@ mail.ru.

3. Sergey Akimov, master of the Department of automobiles and machine-tractor complexes, Federal State Budgetary Educational Institution of Higher Education «Bashkir State Agrarian University», 450001, Ufa, 50-letiya Oktyabrya St., 34, e-mail: hukum2@mail.ru.

4. Ruslan Samikov, master of the Department of automobiles and machine-tractor complexes, Federal State Budgetary Educational Institution of Higher Education «Bashkir State Agrarian University», 450001, Ufa, 50-letiya Oktyabrya St., 34.

When operating a vehicle in sub-zero temperatures, there is always a risk of difficult engine startup and increased operational wear of vehicle components and assemblies. To reduce these effects, various devices and assemblies are used, whose task is to facilitate engine start-up and minimize starting wear. The most common among them are autonomous pre-starting engine heaters. Operating experience in winter has shown that $60 \%$ of preheater failures are related to the state of electronics, fuel quality and wear of rubber products, and failure of the burner components (coking, cracks, burnout). In the conditions of actual operation of these devices, the components of the units and units of the preheater are worn out. In order to diagnose the preheater, a stand is required to check the performance at the nominal operating mode. This article proposes the development of a stand for diagnosing a preheater and measures the time of heating the tested liquid to the operating temperature. For measurements, two Thermmix 15d-24 preheaters are used, one new and the other used, in order to compare the results with each other. Antifreeze is used as the working fluid in the heat exchanger tank. As a result of experiments and comparison of the obtained values of the heating time of the tested liquid to a certain temperature, it was seen that using this stand it is possible to diagnose and check the performance of pre-starting heaters, and a test plan for checking the Thermmix 15d-24 heater was drawn up.

(C) Нигматуллин Ш.Ф., Разяпов М.М., Акимов С.С., Самиков Р.Ф. 